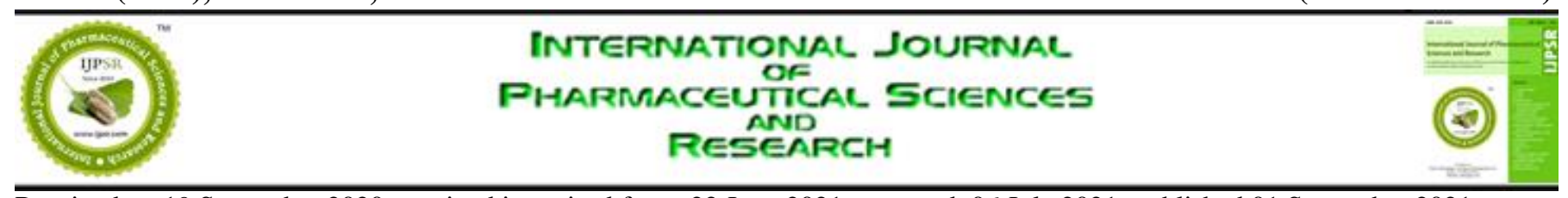

Received on 19 September 2020; received in revised form, 22 June 2021; accepted, 06 July 2021; published 01 September 2021

\title{
A NEW VALIDATED RP-HPLC METHOD FOR SIMULTANEOUS ESTIMATION OF ESOMEPRAZOLE IN BULK AND PHARMACEUTICAL DOSAGE FORM
}

Nellore Dharani Sai Sreekanth *1, Nenavath Adilakshmi ${ }^{2}$, Doddi Anusha ${ }^{3}$, Gurram Sowmya ${ }^{4}$ and Pogaku Surya Teja ${ }^{5}$

Department of Pharmaceutical Analysis * ${ }^{1}$, Sree Dattha Institute of Pharmacy ${ }^{3,4}$, 5, Ibrahimpatnam 501510, Telangana, India.

Department of Pharmaceutical Analysis ${ }^{2}$, Bojjam Narsimhulu Pharmacy College for Women, Hyderabad 500059, Telangana, India.

Keywords:

RP-HPLC, Method Development,

U.V. Spectroscopy, Validation, Accuracy, Precision, ICH Guidelines.

Correspondence to Author:

Mr. Nellore Dharani Sai Sreekanth

Department of Pharmaceutical Analysis, Sree Dattha Institute of Pharmacy, Ibrahimpatnam - 501510, Telangana, India.

E-mail: sreekanth0393@gmail.com

\begin{abstract}
Reverse Phase High-Performance Liquid chromatography is a widely and commonly used analytical method for qualitative and quantitative analysis. A simple, accurate, economical, rapid, and precise RP-HPLC process has been proposed and validated for the determination of esomeprazole in immense bulk and dispensed pharmaceutical drug form. The RP-HPLC separation was achieved on Symmetry ODS RP C18, $5 \mu \mathrm{m}, 15 \mathrm{~mm} \times 4.6 \mathrm{~mm}$ i.d. column using mobile phase Phosphate buffer $(\mathrm{pH}=3.6)$ : $\mathrm{ACN}=50: 50 \mathrm{pH}$ Adjudged with Orthophosphoric acid at continuance effusion of $1.0 \mathrm{ml} / \mathrm{min}$ at ambient temperature. The retention times were observed at $3.797 \mathrm{~min}$ for esomeprazole. The calibration plot is linear beyond the concentration range $0-50 \mu \mathrm{g} / \mathrm{ml}$ for esomeprazole. Quantification was achieved with UV detection at $246 \mathrm{~nm}$ over the Beer-Lambert's range. The proposed methodology is validated statistically as per the ICH guidelines for various validation parameters includes, including Accuracy, Precision, Linearity and range, Limit of detection, and Limit of Quantification. The above method is developed and validated successfully for the routine quantitative analysis of esomeprazole in bulk and pharmaceutical dosage form.
\end{abstract}

INTRODUCTION: Analytical chemistry is The character of sample by knowing concerning employed to determining the qualitative and the presence or absence of sure elements. quantitative composition of the fabric below the study. Both these aspects are necessary to grasp the sample material. Analytical chemistry is split into 2 branches quantitative and qualitative. A qualitative analysis offers us the knowledge regarding.

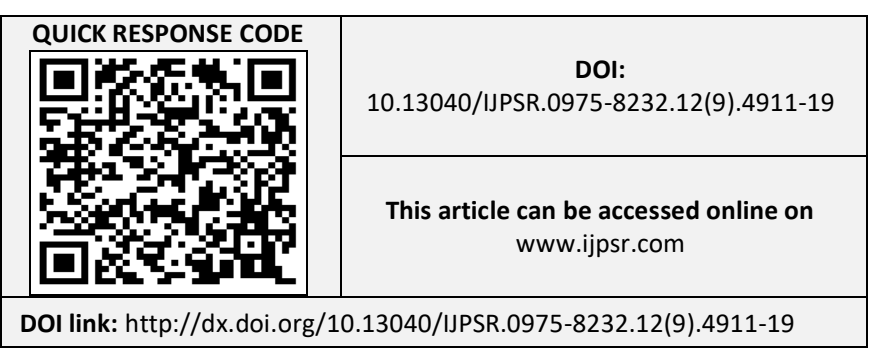

Quantitative chemical analysis provides numerical data on the relative quantity of 1 or a lot of this component ${ }^{1}$. In non-instrumental, the traditional and physicochemical properties are used to investigate the sample.

The instrumental strategies of research are primarily based upon determining the property of substance-using analytical instrument for determining its composition ${ }^{2}$. Chromatography could be a process employed to separate the elements of the mixture by a continuous distribution of the component between 2 phases. 
One section moves (mobile phase) over the opposite phase (stationary phase) continuously. Reverse-phase chromatography is the foremost common mode for analytical and preparatory separations of compound of interest in chemical, biological, pharmaceutical, food and medicine sciences. During this mode, the stationary section is non-polar hydrophobic packing with physicchemical properties of the drug. Octyl or octadecyl functional cluster secure to silica gel and therefore the mobile phase is polar solvent ${ }^{3,4}$. The physical and chemical parameters of a drug play a critical role in the development of a new HPLC method. For method development, it is required that one must study the physical properties like solubility, polarity and $\mathrm{pKa}$ and hydrogen ion concentration of the drug molecule. Polarity could be a property of a compound.

It helps associate analysts to make a decision on the solvent and composition of the mobile section. In a non-polar bond, the electrons are shared equally between 2 atoms. $\mathrm{pH}$ and $\mathrm{pKa}$ play a crucial role in HPLC methodology development ${ }^{5}$. These ways are preferred to make sure to recognize chastity, strength as well as the performance of the drug. There are several factors to think about once developing ways. The bulk of the HPLC development goes into supportive a stabilityindicating HPLC method. The goal of the HPLC method is to undertake and separate quantify the most active drug, any reaction impurities, all on the market artificial intermediates and any degradants.

The most purpose of holding out the strategy development is that, it builds a degree of confidence and conjointly absorbs the shock of variations of analytical conditions and pays for quite invested with on the method ${ }^{6}$. Validation of the analytical procedure is that the method by which it's standard, by practical studies, that the performance characteristics of the procedure carried meet the necessities for its meant use. The strategies validation method for analytical procedures begins with the planned and systematic assortment by the individual of the validation information to support analytical procedures. All analytical methods that are intended are used for examining any samples will be validated. The complete procedure and involved steps is done as per ICH guidelines ${ }^{7}$.
Esomeprazole, sold with the brand Nexium, is a proton pump inhibitor (PPI) medication used for the management of reflux illness (GERD), for internal organ protection to stop repetition of abdomen ulcers or gastric injury from chronic use of NSAIDs. Its effectiveness is taken into account the same as alternative medications inside the PPI category. Esomeprazole exerts its abdomen acidsuppressing effects by preventing the ultimate step in internal organ acid production by covalently binding to sulfhydryl groups of cysteines found on the $(\mathrm{H}+, \mathrm{K}+-\mathrm{ATPase}$ catalyst at the humor surface of viscous membrane bone cells. This impact results in inhibition of each basal and stirred viscous acid secretion, regardless of the stimulant ${ }^{8}$, 9. Elevated intraocular pressure could be a characteristic manifestation of ocular high blood pressure or glaucoma.

The extent of pressure level (IOP) is ruled by the balance between the assembly of humor (by ocular ciliary processes) and its outflow from the anterior section of the eye via trabeculate (conventional) or uveoscleral (unconventional) pathways. Once there's a rise within the resistance to the trabeculate outflow of humor, the pressure level is elevated. Later on, nervus opticus injury will occur from blood flow restrictions and mechanical distortion of ocular structures. Nervus opticus injury will end more in blind spot bloodletting and progressive field of vision loss (and visual impairment in some cases). Esomeprazole is extensively metabolized within the liver by the cytochrome P450 (CYP) catalyst system. The end products of esomeprazole do not have antisecretory functions.

The key part of esomeprazole metabolism relies upon the CYP2C19 isoenzyme, which forms the radical and desmethyl metabolites; the remaining quantity relies on CYP3A4 that forms the sulphone substance 10,11 . The work plan included to undertake solubility and analytical studies of the drug Esomeprazole and develop initial U.V. and chromatographic conditions followed by setting up initial UV and chromatographic conditions for the method development in pure and pharmaceutical dosage forms. Further followed by, Optimization of initial chromatographic and spectrophotometric conditions. Post-optimization, Analytical method validation of the developed RP- HPLC method is carried out. 
MATERIALS AND METHODS:

\section{Materials:}

Instruments Used: HPLC waters with UV-Visible Detector, T60 LAB INDIA UV - Vis spectrophotometer, Electronic Balance (SHIMADZU ATY224), Ultra Sonicator (Wensar wuc 2L), Thermal Oven, Develosil ODS HG-(C18) RP Column, $15 \mathrm{~mm} \times 4.6 \mathrm{~mm}$. PH Analyzer (ELICO), Vaccum filtration kit (BOROSIL).

Reagents Used: Doubled distilled water, HPLC Grade water, Ethanol, DMF, of $99.99 \%$ purity with HPLC Grade were used, which were supplied by Sd. Fine - Chem. Ltd. Mumbai and Methanol and DMSO of $99.99 \%$ purity with HPLC Grade were used which were supplied by Loba Chem. Mumbai.

\section{Methods:}

Solubility Study 12: The solubility study of Esomeprazole was carried out using Acetonitrile, Ethanol, DMF, DMSO, Aqueous buffers and water. The observations are tabulated below in Table $\mathbf{1}$.

TABLE 1: SOLUBILITY OF ESOMEPRAZOLE IN VARIOUS SOLVENTS

\begin{tabular}{cc}
\hline Solvent & Solubility \\
\hline ACN & Soluble \\
Ethanol & Soluble \\
DMF & Soluble \\
DMSO & Soluble \\
Aqueous Buffers & Sparingly Soluble \\
Water & Slightly Soluble \\
\hline
\end{tabular}

Mobile Phase: The mobile section employed in this analysis consists of a mix of Phosphate buffer ( $\mathrm{pH}$ adjusted to 3.6 by orthophosphoric acid) and Acetonitrile during a quantitative relation of 50:50. $500 \mathrm{ml}$ of this solution was superimposed and properly mixed with five hundred cubic centimetres of acetonitrile, and a standardized solution is achieved. Determination of maxima of esomeprazole using UV - Vis spectroscopy ${ }^{13}$.

Standard and Sample Preparation: $10 \mathrm{mg}$ of Esomeprazole normal was transferred into a ten millilitre meter flask, dissolved \& conjure to volume with solvent. Later on, the concentration is reduced by dilution, which was done by transferring one mil of the higher than solution into a $10 \mathrm{ml}$ volumetric flask and form up to volume with solvent. The normal and sample stock solutions were ready one by one by dissolving normal \& sample in an exceedingly solvent by diluting with an equivalent solvent. (After improvement of all conditions) for ultraviolet radiation analysis. This has been performed to understand the maxima of Esomeprazole, in order that an equivalent frequency will be utilized in HPLC ultraviolet radiation detector for estimating the Esomeprazole. Based on the above preparation of standard and sample solutions, Fig. 1. depicts the UV Spectra, and the maximum for the drug esomeprazole was found out to be $246 \mathrm{~nm}$.

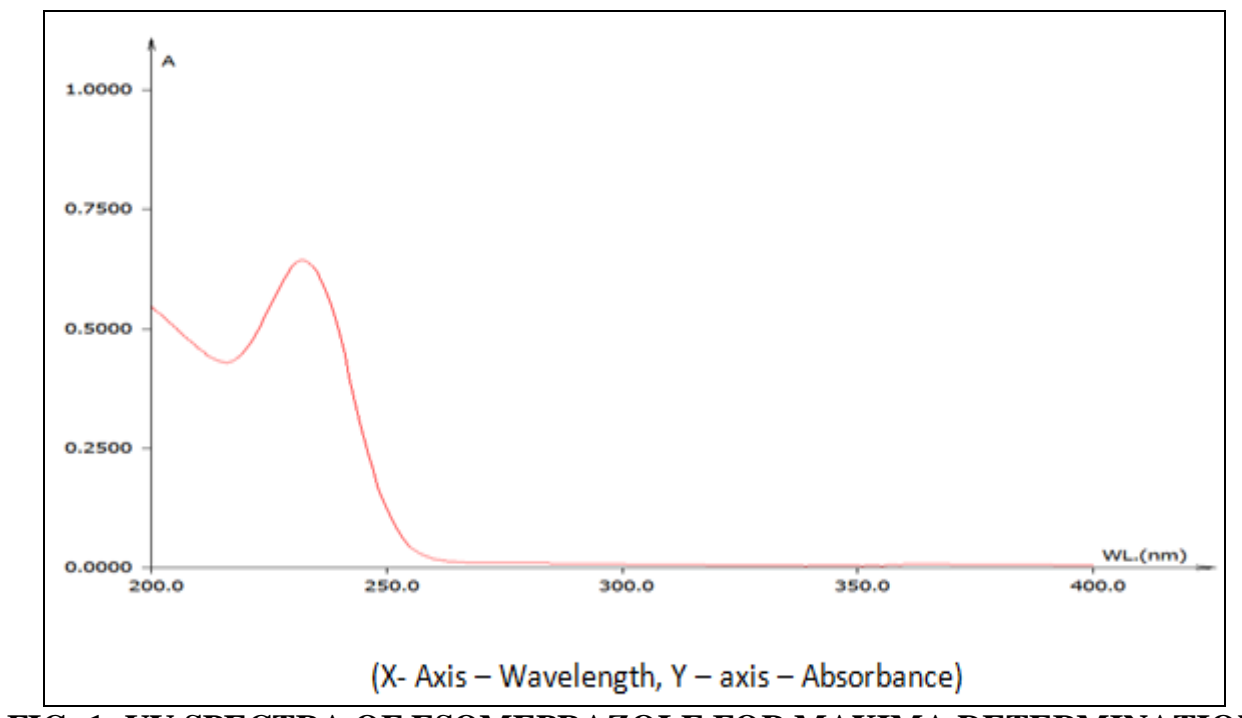

FIG. 1: UV SPECTRA OF ESOMEPRAZOLE FOR MAXIMA DETERMINATION

The maxima for esomeprazole by UV - Vis spectroscopy was found to be $246 \mathrm{~nm}$. Method Development of esomeprazole - Trial 1 (X-axis Minutes, Y-axis - Voltage)
Method Development of Esomeprazole:

Trial 1: The mobile phase which was selected for this trail is Acetonitrile: Water in the ratio of 30: 70 using the column, Develosil ODS HG-5 RP C18, 5 
$\mu \mathrm{m}, 15 \mathrm{~cm} \times 4.6 \mathrm{~mm}$ i.d, with a flow rate of 0.8 $\mathrm{ml} / \mathrm{min}$ and wavelength of $246 \mathrm{~nm}$. Take stock of 10 milligrams of Esomeprazole and shift it into 10 mil metric flask, dissolved and make up the volume with the mobile phase. Later on, the concentration is reduced by dilution, which was done by transferring 1 mil of the prepared solution into a 10 $\mathrm{ml}$ metric flask and form up the volume with mobile phase ${ }^{14}$. This final solution is utilized for recording the observations. The figure and results are shown in Fig. 2. and Table 2.

The efficiency of the chromatogram was not satisfactory, and the peak response was very low; hence, this method is not selected for optimization

Method Development of esomeprazole - Trial 02 (X-axis - Minutes, Y-axis - Voltage)

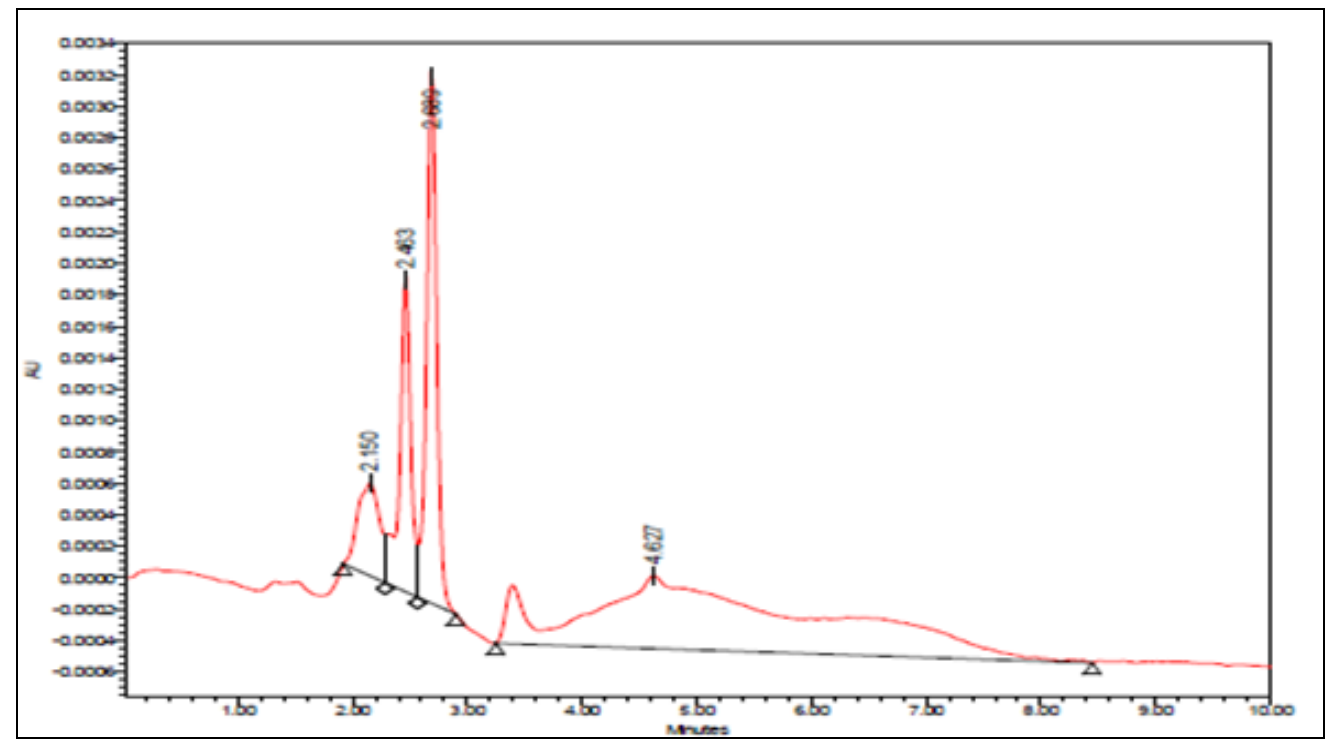

FIG. 2: CHROMATOGRAM - O1 FOR METHOD DEVELOPMENT OF ESOMEPRAZOLE BY RP - HPLC

TABLE 2: PEAK RESULTS

\begin{tabular}{cccc} 
RT & Area & Theoretical Plates & Tailing factor \\
\hline 3.797 & 1048952 & 3125 & 1.02 \\
\hline
\end{tabular}

Trial 2: The mobile phase which was selected for this trail is Acetonitrile: Water in the ratio of 35: 65 using the column, Develosil ODS HG-5 RP C18, 5 $\mu \mathrm{m}, 15 \mathrm{~cm} \times 4.6 \mathrm{~mm}$ i.d, with a flow rate of 1.0 $\mathrm{ml} / \mathrm{min}$ and wavelength of $246 \mathrm{~nm}$. Take stock of 10 milligrams of Esomeprazole and shift it into 10 mil metric flask, dissolved and make up the volume with mobile phase. Later on, the concentration is reduced by dilution, which was done by transferring 1 mil of the prepared solution into a 10 $\mathrm{ml}$ metric flask and form up the volume with mobile phase ${ }^{15}$. This final solution is utilized for recording the observations. The figure and results are shown in Fig. 3. and Table 3.

Trial 3: The mobile phase which was selected for this trial is Phosphate buffer of a $\mathrm{PH}$ 3.6: Acetonitrile in the ratio of 50: 50 using the column, Develosil ODS HG-5 RP C18, $5 \mu \mathrm{m}, 15 \mathrm{~cm} \times 4.6$ $\mathrm{mm}$ i.d, with a flow rate of $1.0 \mathrm{ml} / \mathrm{min}$ and wavelength of $246 \mathrm{~nm}$. Take stock of 10 milligrams of Esomeprazole and shift it into 10 mil metric flask, dissolved, and make up the volume with the mobile phase. Later on, the concentration is reduced by dilution, which was done by transferring $1 \mathrm{ml}$ of the prepared solution into a 10 $\mathrm{ml}$ metric flask and form up the volume with mobile phase ${ }^{16}$. This final solution is utilized for recording the observations. The figure and results are shown in Fig. 4. and Table 4.

Assay: Twenty tablets were taken, and therefore, the I.P. methodology was followed to work out the common weight. Above weighed tablets were finally fine-grained and triturated well. An amount of powder corresponding to $100 \mathrm{mg}$ of medication were transferred to a 100-millilitre meter flask, and seventy ml of HPLC grade methyl alcohol was superimposed, and the solution was sonicated for a quarter-hour, there when the volume was created up to one hundred $\mathrm{ml}$ with the same solvent. Then ten mil of the on top of solution was diluted to one hundred $\mathrm{ml}$ with HPLC grade methanol. The solution was filtered through a membrane filter $(0.45 \mu \mathrm{m})$ and sonicated to degas ${ }^{17}$. From this 
stock solution $(3.5 \mathrm{ml})$ was transferred five different ten mil meter flasks, and volume was created up to $10 \mathrm{ml}$ with the same solvent system. The solution ready was injected in 5 replicates into the HPLC system, and therefore, the observations were recorded. A replica injection of the normal solution was conjointly injected into the HPLC, and there the peak areas recorded ${ }^{18}$. The results are shown in Table 5.

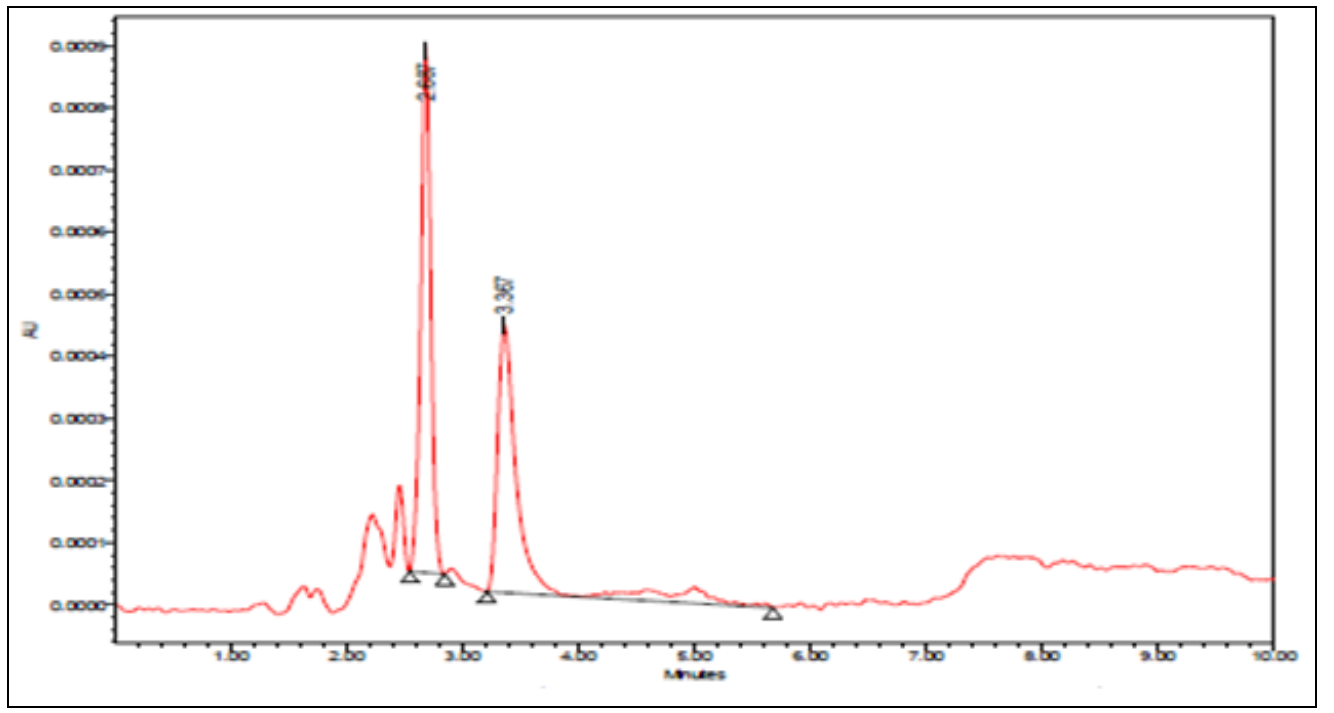

FIG. 3: CHROMATOGRAM - 02 FOR METHOD DEVELOPMENT OF ESOMEPRAZOLE BY RP - HPLC

TABLE 3: PEAK RESULTS

\begin{tabular}{cccc}
\hline RT & Area & Theoretical Plates & Tailing factor \\
\hline 2.687 & 1248952 & 3582 & 1.28 \\
3.367 & 1536524 & 3712 & 1.06 \\
\hline
\end{tabular}

The efficiency of the chromatogram was not satisfactory, and the dual peaks response have been observed; hence, this method is not selected for optimization

Method Development of esomeprazole - Trial 3: (X-axis - Minutes, Y-axis - Voltage)

TABLE 4: PEAK RESULTS

\begin{tabular}{cccc}
\hline RT & Area & Theoretical Plates & Tailing factor \\
\hline 3.797 & 1048952 & 3125 & 1.02 \\
\hline
\end{tabular}

The efficiency of the chromatogram was not satisfactory, and the dual peaks response have been observed; hence, this method is not selected for optimization

Method Development of esomeprazole - Trial 3: (X-axis - Minutes, Y-axis - Voltage)

\section{Validation 19:}

System Suitability: System suitability testing is an integral part of several analytical procedures. The conception supports the tests that the instrumentation, analytical operations, and samples to be analyzed represent an integral system that may be evaluated in and of it. The results are shown in Table 11.

Accuracy: To determine the accuracy of the planned methodology, recovery studies were carried out by adding totally different amounts $(80 \%, 100 \%$, and $120 \%)$ of pure drug of Esomeprazole were taken and value-added to the pre-analyzed formulation of concentration 50 $\mu \mathrm{g} / \mathrm{ml}$. From that, percentage recovery values were calculated. The results are shown in Table 6.

\section{Precision:}

Repeatability: The precision of each methodology was determined one by one from the peak areas and retention times obtained by actual determination of six replicates of a set quantity of the drug. Esomeprazole (API). The \% relative normal deviations were calculated for Esomeprazole. The results are shown in Table 7.

Intermediate Precision: The Intermediate Precision Consists of 2 Methods. Intraday in the Intra Day method, the $40 \%, 50 \%$, and $60 \%$ concentrations are injected at completely different intervals of time in same day. Inter Day: In inter Day method; the $40 \%, 50 \%$ and $60 \%$ concentration are injected at same intervals of time in different days. The results are shown in Table 8. 


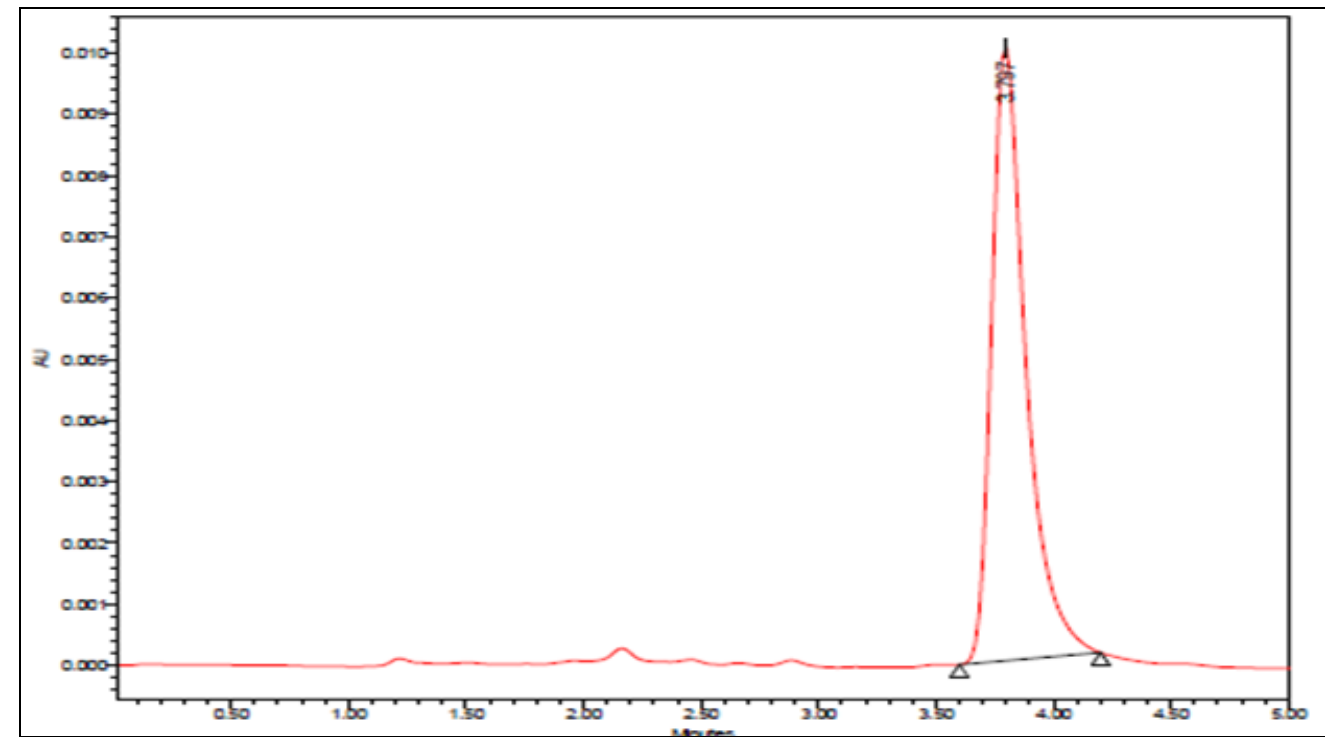

FIG. 4: CHROMATOGRAM - O3 FOR METHOD DEVELOPMENT OF ESOMEPRAZOLE BY RP - HPLC

TABLE 5: RESULTS OBTAINED FROM ASSAY OF ESOMEPRAZOLE BY HPLC

$\begin{array}{lccc}\text { Brand name of Injection } & \begin{array}{c}\text { Labelled amount of } \\ \text { Drug }(\mathrm{mg} / \mathrm{ml})\end{array} & \begin{array}{c}\text { Mean }( \pm \mathrm{SD}) \text { amount }(\mathrm{mg} / \mathrm{ml}) \text { found } \\ \text { by the proposed method }(\mathrm{n}=6)\end{array} & \text { Assay + \% RSD }\end{array}$

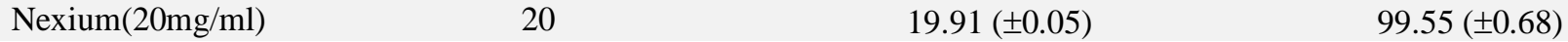

Here the peaks were separated and showed better resolution, theoretical plate count, and symmetry. The proposed chromatographic conditions were found appropriate for the quantitative determination of the drug.

Assay: The amount of drug in Nexium $(20 \mathrm{mg} / \mathrm{ml})$ Injection was found to be $19.91 \pm 0.05) \mathrm{mg} / \mathrm{tab}$ for Esomeprazole and \% assay was $99.55 \%$.

\section{Method Validation:}

Accuracy: From the Accuracy Method, we observed that the \%Recovery of the drug is within the range of $98-102 \%$ i.e., $99.448 \%$, $100.388 \%, 100.596 \%$. And the \% RSD is <2 i.e. $1.812323 \%, \quad 0.629776 \% \%$ and $1.700836 \%$ respectively.

Linearity \& Range: To assess the linearity, serial dilution of analyte were ready from the stock solution was diluted with mobile section to induce a series of concentrations starting from 20-70 $\mu \mathrm{g} / \mathrm{ml}$. The prepared solutions were filtered through Whatman paper (No.41). From these solutions, 10 $\mu l$ injections of every concentration were injected into the HPLC system and chromate was graphed below the optimized conditions. A calibration curve was made by plotting the mean peak area (Yaxis) against the concentration (X-axis). The figure and results are shown in Fig. 5. and Table 9.

TABLE 6: RESULTS OBTAINED FROM ACCURACY OF ESOMEPRAZOLE (\% RECOVERY AND STATISTICAL ANALYSIS)

\begin{tabular}{cccccc}
\hline S. no & Pure drug & Peak Area & Conc Found & \% Recovery of Pure drug & Statistical analysis \\
\hline $\mathrm{S}_{1}: 80 \%$ & 40 & 251621 & 39.3753 & 98.43826 & Mean $=99.448 \%$ \\
$\mathrm{~S}_{2}: 80 \%$ & 40 & 251465 & 39.35089 & 98.37722 & S.D. $=1.0823199$ \\
$\mathrm{~S}_{3}: 80 \%$ & 40 & 259521 & 40.61161 & 101.529 & R.S.D.= $1.812323 \%$ \\
$\mathrm{~S}_{4}: 100 \%$ & 50 & 318512 & 49.84338 & 99.68675 & Mean $=100.388 \%$ \\
$\mathrm{~S}_{5}: 100 \%$ & 50 & 321312 & 50.28156 & 100.5631 & S.D. $=0.63222$ \\
$\mathrm{~S}_{6}: 100 \%$ & 50 & 322434 & 50.45715 & 100.9143 & R.S.D.= $0.629776 \%$ \\
$\mathrm{~S}_{7}: 120 \%$ & 60 & 381475 & 59.69674 & 99.49457 & Mean $=100.596 \%$ \\
$\mathrm{~S}_{8}: 120 \%$ & 60 & 382365 & 59.83602 & 99.7267 & S.D. $=1.710973$ \\
$\mathrm{~S}_{9}: 120 \%$ & 60 & 393256 & 61.5404 & 102.5673 & R.S.D. $=1.700836 \%$ \\
\hline
\end{tabular}

Method Robustness: Influence of minor changes in chromatographic parameters reminiscent of modification in rate of flow $( \pm 0.1 \mathrm{ml} / \mathrm{min})$,
Wavelength of detection $( \pm 2 \mathrm{~nm})$ \& organic section content in the mobile phase $( \pm 2 \%)$ studied to work out the hardiness of the strategy are also in 
favour of the developed RP-HPLC technique for the analysis of Esomeprazole (API). The results are shown in Table $\mathbf{1 0 .}$

Limit of Detection and Limit of Quantification (LOD \& LOQ): 20

The detection limit of a private analytical procedure is that the lowest quantity of analyte may be detected, however not essentially quantitated as a precise worth. The limit of quantitation is outlined because of the lowest concentration of associate.

Analyte which will be determined with acceptable preciseness and accuracy underneath the explicit operational conditions of the method.

TABLE 7: RESULTS OBTAINED FROM PRECISION OF ESOMEPRAZOLE (STANDARD DEVIATION AND \% RSD)

\begin{tabular}{ccc}
\hline HPLC Injection & Retention Time & Area \\
Replicates of Esomeprazole & 3.797 & 106134 \\
Replicate -1 & 3.799 & 105762 \\
Replicate -2 & 3.801 & 103536 \\
Replicate -3 & 3.802 & 105762 \\
Replicate -4 & 3.805 & 101767 \\
Replicate -5 & 3.803 & 103256 \\
Replicate -6 & 3.801166667 & 10436986.5 \\
Average & 0.002857738 & 177195.3912 \\
Standard Deviation & 0.07518 & 1.697763921 \\
\% RSD & & \\
\hline
\end{tabular}

Precision - Repeatability: From the Precision method, we observed that the \% RSD of the AUC is 1.697763921 and RT is 0.07518, which are within the acceptable range as per ICH guidelines.

TABLE 8: RESULTS OBTAINED FROM INTERMEDIATE PRECISION OF ESOMEPRAZOLE (INTRADAY AND INTERDAY)

\begin{tabular}{ccccc}
\hline $\begin{array}{c}\text { Conc. Of } \\
\text { Esomeprazole } \\
(\mathbf{A P I})(\boldsymbol{\mu g} / \mathbf{m l})\end{array}$ & \multicolumn{2}{c}{$\begin{array}{c}\text { Observed Conc. Of Esomeprazole }(\boldsymbol{\mu g} / \mathbf{m l}) \\
\text { Intra-Day the proposed method } \\
\text { Inter-Day }\end{array}$} \\
\hline 40 & 39.8 & \% RSD & Mean (n=6) & \% RSD \\
50 & 59.8 & 0.39 & 37.8 & 0.38 \\
60 & 60.01 & 0.58 & 59.7 & 0.57 \\
\hline
\end{tabular}

Intermediate precision: The intra \& inter-day variation of the method was carried out \& the high values of mean assay \& low values of standard deviation \& \% RSD (\% RSD < 2\%) within a day \& day to day variations for Esomeprazole revealed that the proposed method is precise.

\section{Linearity and Range:}

TABLE 9: RESULTS OBTAINED FROM LINEARITY OF ESOMEPRAZOLE

\begin{tabular}{cc}
\hline CONC. $(\boldsymbol{\mu g} / \mathbf{m l})$ & MEAN AUC $(\mathbf{n}=\mathbf{6})$ \\
\hline 0 & 0 \\
30 & 189804 \\
40 & 248924 \\
50 & 318701 \\
60 & 390994 \\
70 & 441497 \\
\hline
\end{tabular}

Linearity and Range: We observed that the curve showed good linearity in the range of $10-50 \mu \mathrm{g} / \mathrm{ml}$, for Esomeprazole (API) with a correlation coefficient (R2) of 0.999. A typical calibration curve has the regression equation of $y=6390 x+$ 1282 for Esomeprazole.

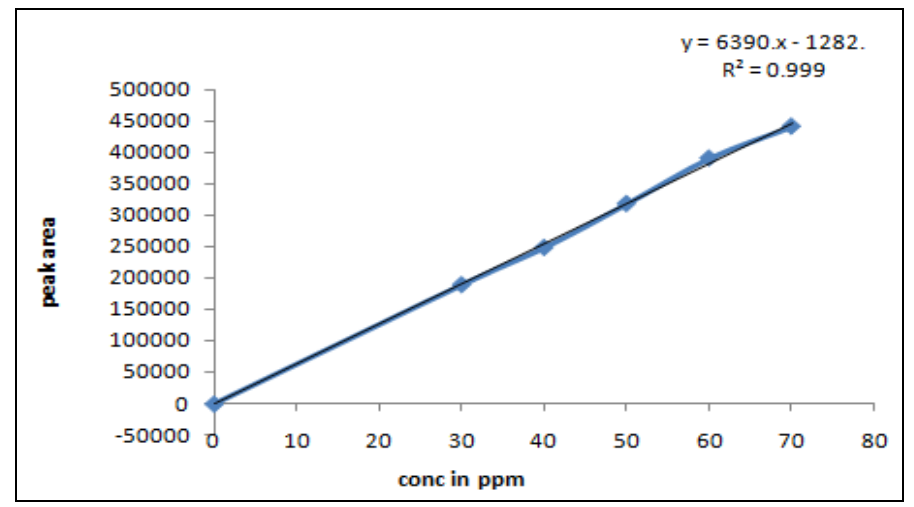

FIG. 5: LINEARITY GRAPH OF ESOMEPRAZOLE

RESULTS AND DISCUSSIONS

Determination of Maxima of Esomeprazole Using UV - Vis Spectroscopy:

Method Robustness: 
TABLE 10: RESULTS OBTAINED FROM METHOD ROBUSTNESS OF ESOMEPRAZOLE

\begin{tabular}{cc}
\hline Change in parameter & \% RSD \\
\hline Flow $(1.1 \mathrm{ml} / \mathrm{min})$ & 0.35 \\
Flow $(0.9 \mathrm{ml} / \mathrm{min})$ & 0.39 \\
More Organic & 0.16 \\
Less Organic & 0.09 \\
Wavelength of Detection $(248 \mathrm{~nm})$ & 0.27 \\
Wavelength of detection $(244 \mathrm{~nm})$ & 0.37 \\
\hline
\end{tabular}

\section{System Suitability:}

TABLE 11: SYSTEM SUITABILITY PARAMETERS RESULTS OF ESOMEPRAZOLE

\begin{tabular}{cccc}
\hline S. no & Parameter & Limit & Result \\
\hline 1 & Resolution & Rs $>2$ & 9.15 \\
2 & Asymmetry & $\mathrm{T} \leq 2$ & Esomeprazole $=0.12$ \\
3 & Theoretical plate & $\mathrm{N}>2000$ & Esomeprazole $=3246$ \\
\hline
\end{tabular}

CONCLUSION: A sensitive \& selective RPHPLC method has been developed and validated to analyze esomeprazole API. Further, the proposed RP-HPLC method has excellent sensitivity, precision, and reproducibility.

The result shows the developed method is yet another suitable method for assay purity, which can help analyze esomeprazole in different formulations.

ACKNOWLEDGEMENT: The authors are thankful to SD fine Chem. Ltd, Mumbai and Loba Chem. Ltd Mumbai for providing with necessary solvents to carry out the experiment work. The authors are also thankful to Sree Dattha Institute of Pharmacy for providing the necessary lab space to complete the experiment work.

CONFLICTS OF INTEREST: The authors declare no conflicts of interest.

\section{REFERENCES:}

1. Y Venkateswara Rao and K Sujana: A novel stability indicating rp-hplc method development and validation for the determination of clopidogrel in bulk and its dosage forms. International Journal of Pharmacy Research and Technology 2019; 2: 1-11.

2. Michael W Dong: HPLC method development. Wiley Publishers Second Edition 2019; 245-76.

3. United states pharmacopoeia and national formulary, (24th) asian edition. The United States Pharmacopoeia Convention Inc USA 2126.

4. Sandya Rani G, P Shiva Sagar, A Madhuri and Mallikarjun: Development and validation of rp-hplc method for donepezil hcl in pharmaceutical dosage forms. Journal of Global trends in Pharmaceutical Sciences 2020; 11(4): 8748-53.
5. Sufiyan Ahmad, Sharma Deepika, Patil Amol, Warude Kapil, Md Rageeb and Md Usman: Novel rp - hplc method development and validation of meloxicam suppository. Indian Journal of Pharmaceutical Education and Research 2017; 51(4): 644-49.

6. Kalkotwar RS and Laghave PK: RP-HPLC method development and validation for determination of labetelol in bulk and marketed formulation. Current Pharma Research 2018; 8(3): 2447-57.

7. Ali Gamal Ahmed Al-Kaf and EL-Rashed Ahmed Gad kariem: Development and validation of an rp-hplc method for estimation of secnidazole and its degradation products in tablets. Global Journal of Pharmacy and Pharmaceutical Sciences 2016; 1(1): 1-9.

8. G Mounika and Dr Subhas Sahoo: Estimate gliclazide simultaneously in tablet dosage form by RP-HPLC. International Journal of Advanced research in Medical and Pharmaceutical Sciences 2020; 5(2): 1-8.

9. Khalil Ghadir A, Salama, Ismail Gomaa and Mohammed S: Validated RP - Hplc method for simultaneous determination of canaglifozin, dapagliflozin, empagliflozin and metformin. International Journal of Pharmaceutical, Chemical and Biological sciences 2018; 8(1): 1-13.

10. Dure Najaf Iqbal, Adeel Ashraf, Munawar Iqbal and Arif Nazi: Analytical method development and validation of hydrocortisone and clotrimazole in topical dosage form using RP-HPLC. Future Journal of Pharmaceutical Sciences 2020; 49(6): 1-7.

11. Suraj R Chaudhari and Atul A Shrikhedkar: Design of experiment avenue for development and validation of RPHPLC-PDA method for determination of Apremilast in bulk and in in-house tablet formulation. Journal of Analytical Science and Technology 2019; 10(10): 1-9.

12. Roshan Pradhana, Tuan Hiep Trana, Sung Yub Kima Kyu, Bong Wooa Yong, Joo Choia, Han-Gon Choib and Chul Soon Yong: Preparation and characterization of fast dissolving flurbiprofen and esomeprazole solid dispersion using spray drying technique. International Journal of Pharmaceutics 2016; 1(2): 38-46.

13. Tej Kumar Kokkirala and Duvvuri Suryakala: RP-HPLC method development and validation for the estimation of emtricitabine, bictegravir and tenofovir alafenamide in bulk and pharmaceutical dosage form. Journal of Taibah University for Science 2019; 13(1): 1137-46.

14. Jyothi Uppalapati and Umadevi Parimi: Stability indicating rp-hplc method for simultaneous estimation of sacubitril and valsatran in drug product. Journal of Pharmaceutical Sciences and Resea 2018; 10(9): 2201-04.

15. Gali Haritha and Yerragunta vishwanadham: Development and validation of RP-HPLC for simultaneous estimation of naproxen and esomeprazole in pharmaceutical dosage form. Asian J of Research in Chemistry 2016; 8: 366-68

16. Farah Khan, Irshad Ahmad, Muhammad Akhtar, Heena Abdul Rauf, Hamza Altaf and Muhammad and Munawar Hayat: RP-HPLC method development and validation for simultaneous determination of esomeprazole and diclofenac sodium in pharmaceutical dosage forms. Pharmaceutical Chemistry Journal 2016; 49: 788-94

17. Shoaeb Mohammad Syed, RP Marathe and PR Mahaparal: Analytical Method Development And Validation Of RPHPLC Method For Determination Of Eletriptan Hbr. Current Pharma Research 2019; 10(1): 3535-42.

18. Anees Ayesha, Bahazeq Asra Ali and Akbar Syed: Development and validation of memantine hydrochloride by rp-hplc method. Asian Journal of Pharmaceutical Research 2019; 9(2): 69-74. 
19. Adel Ehab Ibrahim, Hanaa Saleh and Magda Elhenawee: Assessment and validation of green stability indicating RP-HPLC method for simultaneous determination of Timolol and Latanoprost in pharmaceutical dosage forms using eco-friendly chiral mobile phase. Microchemical Journal 2019; 148: 21-26.
20. Rahul K Godge, Ganesh S Shinde and Shraddha Joshi: Simultaneous estimation and validation of dapagliflozin and saxagliptin in bulk drug and dosage form by rp - hplc. Research Journal of Science and Techn2018; 11(1): 59-63.

How to cite this article:

Sreekanth NDS, Adilakshmi N, Anusha D, Sowmya G and Teja PS: A new validated rp-hplc method for simultaneous estimation of esomeprazole in bulk and pharmaceutical dosage form. Int J Pharm Sci \& Res 2021; 12(9): 4911-19. doi: 10.13040/IJPSR.09758232.12(9).4911-19.

All $\odot 2021$ are reserved by International Journal of Pharmaceutical Sciences and Research. This Journal licensed under a Creative Commons Attribution-NonCommercial-ShareAlike 3.0 Unported License.

This article can be downloaded to Android OS based mobile. Scan QR Code using Code/Bar Scanner from your mobile. (Scanners are available on Google Playstore) 